\title{
School students, information retrieval and transfer
}

\author{
James Edward Herring
}

\begin{abstract}
This study sought to examine the views of students, teachers and teacher librarians on students' attitudes to, use of, and reflections on, information retrieval, when completing curricular assignments. A second element of the research was to investigate the views of students, teachers and teacher librarians on the extent to which students might transfer information retrieval skills across time and across subjects. The research was carried out in three rural Australian schools. A constructivist grounded theory approach was taken in the study, and data was collected in the form of student diaries and questionnaires, and interviews with students and staff. Constructivist grounded analysis was used to analyse and interpret data. Findings from the study indicated that a minority of students both valued and would transfer information retrieval skills; the majority of students valued information retrieval skills but were unlikely to transfer skills without prompting; and a very small minority of students could not understand the concepts of information retrieval and transfer. The study also found that the schools lacked a culture of transfer.
\end{abstract}

\section{Introduction}

In today's secondary/high schools, there is much anecdotal evidence, and some research evidence, that, while students are experienced users of the web, they are not necessarily effective users. There is also anecdotal evidence that teachers assume that students, for example because of their age, will be effective users of the web. This anecdotal evidence also shows that both teachers and teacher librarians assume that, if students are taught how to be effective web searchers, students will transfer both attitudes to web searching and information retrieval skills across time and subjects. This study sought to explore the issues relating to this apparent contradiction i.e. that teachers' assumptions did not match the reality of student use of the web. The context of this paper is a wider study by the author of the use of information literacy skills by year seven (first year high/secondary school) students in three rural Australian schools. The paper will also draw on previous research conducted by the author of year seven and eight students' use of

\section{James Edward Herring}

Dr James Herring is part of the teacher librarianship team at Charles Sturt University. His research has focused on information literacy and ICT in schools. *Note: The author works for 10 months of the year from his home in Scotland, and 2 months in Australia. Thus the different corresponding address in his profile.

Email: jherring@csu.edu.au

Received 02 June 2010

Accepted 26 August 2010 
information retrieval in UK secondary schools. While the wider study examined students' views on and use of a range of information literacy skills (e.g. students' definition of purpose, question formulation, concept mapping, information evaluation, note taking and assignment writing), this paper focuses on students' approaches to information retrieval, particularly from the web, as well as issues relating to the transfer of information retrieval skills.

\section{$2 \quad$ Literature Review}

\section{Information literacy}

There are many definitions of information literacy and the questions posed by Langford (1998) are still relevant today. Langford's (1998) questions are "Is it [information literacy] a concept or a process? ... Or is it a new literacy that has been transformed from existing literacies to complement the emerging technologies for which the Information Age students must be skilled?" The present author defines information literacy as a critical and reflective ability to exploit the current information environment, and to adapt to new information environments; and as a practice. This definition views information literacy as an ability and a practice, as opposed to a set of skills (e.g. information retrieval skills) which students will use both in and outside school. If information literacy is seen as a critical and reflective ability, then students who engage, for example, in web searching, will have the ability use a set of skills they have learned. However, these skills will not be used mechanically and students will engage in critical thinking about which skills to use and will reflect on why they might use particular skills i.e. they will be effective practitioners. Williams' (2001) criticism of some definitions of information literacy also remains relevant today, in that she questioned the connection between what was described as information literacy and student learning.

Information literacy has been one of the most widely discussed topics in the literature of teacher librarianship. While much of this literature is related to practice in schools, there is a growing body of research related to information literacy with key authors including Kuhlthau (2004), Todd (2007), Farmer (2005), Barranoik (2004), Author (2006), Wolf (2007) and Woolls and Loertscher (2002). These authors have examined cognitive as well as affective aspects of information literacy, information literacy models and their use in schools. They have also focused on students' use of information literacy skills and techniques, such as defining purpose, concept mapping, question formulation, information seeking and evaluation of sources and content, note taking strategies, and the planning and writing of curricular assignments. Loertscher (2008) noted that despite the wide range of research and publications, a number of issues relating to information literacy remain unresolved. The issue of students' transferring information literacy skills across time and subjects, has been largely ignored in the literature, where there are assumptions about students transferring information literacy skills, but little empirical evidence of transfer taking place. The study by Author and Hurst (2006) examined students' attitudes to transfer in a primary school and identified some evidence of the transfer of skills from one term to another. This study was limited in size as only one class was studied, and the methodology was also limited. 


\section{Information retrieval}

An examination of student views on information retrieval was part of research by Author, Tarter and Naylor (2002), Author (2006), Author and Hurst (2006) and Author and Tarter (2007). These studies, which evaluated aspects of students use of Author's (1996 and 2004) PLUS (Purpose, Location Use and Self evaluation) model showed that, while a minority of students used relatively sophisticated information retrieval skills, for both digital and print resources, most students had a very limited approach to information retrieval, especially when using search engines. Kuhlthau (2004) reported on a range of studies into information retrieval, including the development of the Information Search Process (ISP). Kuhlthau's (2004, p. 37) research introduced a new focus on factors affecting students' information retrieval, by studying the affective aspects such as 'thoughts, feelings, actions, strategies and mood'. Bilal, Sarangthem and Bachir (2008) focused on information seeking in digital libraries and their conclusions include a reaffirmation of Kuhlthau's (2004) findings on uncertainty and satisfaction in relation to information retrieval. . Chung and Neuman (2007) studied high school students' approaches to information retrieval, finding that $11^{\text {th }}$ grade students' understanding of topics increased during information seeking. Myers, Nathan and Saxton (2006) examined barriers to information seeking in school libraries, and these barriers included insufficient collaboration between students and a lack of focus on students' previous information retrieval activities. Chelton and Cool (2004) presented a range of research studies, mainly from North America, on how children and adolescents seek information in a variety of contexts. Gross (2004) examined how primary school children coped with finding information for school assignments, and argued that more emphasis should be put on students framing their own questions prior to information retrieval. Some of these studies focused narrowly on one school or group of students and some lacked a clear theoretical perspective. None of the studies cited here focused on the potential transfer of information retrieval skills across time and across the curriculum. In these studies, as in schools in general, there is often an assumption that students will transfer the skills they have been taught, with some studies predicting that students will, once they learn how to retrieve information effectively, use these new skills in the future. The present study shows this assumption to be false.

\section{Transfer}

While there has been much research on information seeking and retrieval in schools, these studies have not focused on information retrieval in relation to transfer in any depth. There is much implied attention given to the concept of transfer in relation to information retrieval, but there is little coverage of this issue in the literature. Detterman (1993), Haskell (2001), Royer, Mestre and Dufresne (2005) and Hakel and Halpern (2005) discussed definitions, theories and types of transfer in educational settings. These authors present a range of findings about the transfer of knowledge and skills in schools, and conclusions range from the mainly negative views of Detterman (1993) to the more positive views of Royer et al (2005). The more recent studies of transfer have taken a wider sociocultural view of transfer than earlier studies. Royer et al (2005) argued that transfer should be viewed as how learning in one situation has an influence on subsequent learning, and that a variety of factors need to be considered when studying 
transfer. The present study takes a sociocultural perspective on factors influencing information literacy skills. One element identified by Haskell (2001) is the importance of having a culture of transfer in schools. In the context of this study, a culture of transfer would imply that teachers, teacher librarians and students were committed to focusing on the transfer of information retrieval skills as a key aspect of information literacy development in the school.

\section{$3 \quad$ Methodology}

A constructivist grounded theory approach was taken to the study, and constructivist grounded analysis was used to analyse and interpret the gathered data. Constructivist researchers (Philips 1995 and Pidgeon and Henwood 2004) regard knowledge as well as data collection and analysis, as being constructed by individuals, and take the view that researchers interpret the constructions of reality which research participants offer. Grounded theory has progressed from the early work of Glaser and Strauss (1967) to Strauss and Corbin (1998), and constructivist grounded theory has been most influenced by Charmaz (2006). The key elements of constructivist grounded theory are that the researcher is viewed as an interpreter of the observed world and that data, such as student interviews, is viewed as construction of reality by participants in the study. The researcher examines what emerges from the data and does not approach the study with a preconceived hypothesis. According to Charmaz (2006), grounded theorists seek to explain studied phenomena but do not seek to generalise from their findings.

The data for this study, part of a larger study as noted above, was gathered using student diaries, student questionnaires and interviews with students, teachers and teacher librarians in three rural Australian schools. The data relevant to information retrieval and transfer has been selected from the larger study. Students completed structured diaries when completing a history assignment in term three of the school year. Students completed the questionnaires after finishing a term four assignment in English, Japanese or Science, depending on their school. Students were interviewed at the end of term four. Teachers and teacher librarians were interviewed at the start of term three. Following grounded theory (Charmaz 2006) methods, the author engaged in theoretical sampling and interviewed staff and students in term two of the following year. Theoretical sampling seeks to test the categories identified by the researcher by going back into the research field.

Data was analysed using grounded theory methods (Charmaz 2006 and Pidgeon and Henwood 2004). All data was coded, and categories were identified and tested using both initial and focused coding of diary, questionnaire and interview data. Categories were then re-tested, using theoretical sampling interviews. Coding of these interviews produced the final categories (e.g. students valuing information retrieval skills) which are discussed below. In the larger study, a grounded theory relating to information literacy skills and transfer was developed, and elements of that theory are included in the discussion section of this paper. 


\section{$4 \quad$ Findings}

The findings of the study are presented as follows: student diaries and information retrieval; student questionnaires and information retrieval; student interviews and information retrieval and transfer; and staff interviews and information retrieval and transfer.

\section{Student diaries - information retrieval}

In relation to finding information sources, student responses were fairly general about how they found books to use for their assignment. Some students in each school used books which had been found by other students and comments included 'We found a book about knights and talked about it in our group', while other students, a minority, asked the teacher or teacher librarian. Students were also fairly general in their comments about finding websites. For example, while some students used a search engine ("It was easy - just typing in what you wanted to find out for your topic"), many others were less specific ("I looked at different websites").

Students' diary comments on finding information relevant to their topic were more specific. Some students used specific keywords ('I Googled to find out about food and clothes in the medieval village' and phrases ('I put in the cruellest dictator as I thought that would give me good stuff'). Other students' searches were more generalised and most students appeared to do limited searches and then browse though websites. Students were asked to comment on how successful they thought their searching had been. Most students stated that they had been successful in finding the right information for their topic, but it was unclear how the students might have interpreted the term successful.

\section{Student questionnaires - information retrieval}

Students were asked how they found the right information for their term four assignment. This question was phrased with an emphasis on right, as there was some misinterpretation of this issue in the student diaries. Results showed that students' strategies, in rank order of number selected, were:

Finding a book which covered the topic (33 students)

Searching the web using topic keywords (28)

Using the school library OPAC (21)

Talking to other students and finding better information from them (10)

When students were asked to identify how they selected relevant information from websites, the results were:

Browsing through the website (27 students)

Using keywords (24)

Looking at the title of the site (23)

Ignoring information that wasn't relevant to their topic (14)

Referring to their mind map or questions (5) 
In the questionnaire, students were asked to comment on whether they had used the information literacy skills which they had been taught in term three and $70 \%$ of students responded positively, $26 \%$ responded negatively and $4 \%$ responded 'I don't know'. When asked to provide examples of skills which they had transferred, the highest ranked skill was information seeking and retrieval. Comments included 'I learned different ways to find information in websites', and 'I'm now much better at finding good information for my assignments'.

While there was some evidence of the transfer of information retrieval skills, the questionnaire responses lacked depth and issues raised by the questionnaire data were followed up in the student interviews.

\section{Student interviews - information retrieval and transfer}

In the first set of interviews, in terms of searching for information, students mainly referred to searching within books, but searching for and within websites. Despite the claims in the questionnaires about the use of the library catalogue, none of the students interviewed referred to the OPAC, but it may be possible that these students were not a representative sample of OPAC users. In all three schools, students referred to using keywords, both to search for information in books and in websites, and comments included 'Well, you think about what you want to find and you use your keywords - like you'll try to find your keywords in the site'. Students stated that they used keywords when searching for information on the web, and almost all students who cited a search engine, named Google although one student cited Dogpile. The students interviewed mostly appeared to be aware of the importance of searching under more than one keyword e.g.:

[First student] If you only put in one word, it's not really a good idea as it might not come up with the right information or the right websites. If you only put in tyrants - well, anything can come up because it's all around the world. [Second student] You need to put in more than one word if you really want to get good results.

The less articulate students in the groups tended to use a one word approach e.g. "You just put your topic into Google and that's all you need".

Students also discussed their strategies for identifying relevant information in a website and, in particular, skimming and scanning skills - although the students tended to use these terms interchangeably. A School C student explained "You read through the site and think about whether it's got to do with your questions because sometimes it looks like it will be good, but then it turns out to be something different".

The students interviewed appeared to be confident about using information retrieval skills, but an interesting development in the first student interviews was that the students in all three schools referred to a lack of information retrieval skills in other students. This issue emerged when discussing the transfer of skills. For example, most of the students interviewed argued that they had transferred skills, such as information retrieval skills, and that teachers would not need to reinforce such skills. In relation to other students, however, most of the students interviewed that for many students in their class, reinforcement was necessary. A typical comment was 'Some people - mainly boys - they just want to get into the 
work right away, so they rush into it. So it would better for them to be told by the teacher to think about how they can best find information - to slow them down'.

In the theoretical sampling interviews, where the researcher sought to test the categories identified from the coded data, one of the categories discussed was Thinking about information retrieval. The students argued that some of their fellow students were adept at thinking about information retrieval in order to get the most relevant information, and one School B student summed this up, stating:

Well, if you don't think about it, you won't get what you need, will you? Some students are really good at this and find it really easy to get the right information but sometimes it can be hard - but, like if you think about it and don't rush it, you'll get there.

All three groups argued that there were some students - there was no attempt to identify numbers of students - who did not approach information retrieval with sufficient thought or planning. This is illustrated by two School C students who discussed this:

[First student] Yeah, some do but there are some that just want to get it over and done with, so they don't think about getting the best information. They just plagiarise and take stuff off the internet and write it into their assignments. [Second student] Yeah, I agree - they just take things from books and stuff and want to get it over and done with quickly. [First student] Yeah and get on with other things - like, not work. [Second student] Yeah, maybe some of them - they think about getting the best information but they don't go through with it because they think it's going to be harder.

Other students in the groups concurred with this view, and used phrases such as "they rush in", or "they want to get it over quickly", and agreed with the School C group above that this led to some students to selecting the first websites which appeared when they did a search. In relation to a second category, Valuing information literacy skills, students made the same distinction between student who valued information retrieval skills, and put them into practice, and those who valued information retrieval skills, but did not put them into practice.

When students discussed the transfer of skills, they reiterated the distinction between students who were motivated to transfer information retrieval skills and students who needed to be reminded by teachers and teacher librarians about information strategies. The students emphasised that it was the teachers' and teacher librarians' responsibility to motivate more students, for example by developing more interesting assignments and reinforcing skills. One student summed up the views of students, stating 'So if you could do revision on what we're talking about here [information retrieval skills], just like we get revision after we've done certain things in maths - so you could get revision after we've done an assignment'.

\section{Staff interviews - information retrieval and transfer}

In the first interviews with teachers, all but one of the teachers expressed confidence in the students' ability to effectively search for information using Google. The teachers did not define 'effectively' but assumed a high level of 
ability. Only the science teacher in School A took a less optimistic view, stating 'There are some students who can use the internet very competently and even to the point of knowing what are good sites and what aren't. There are others who can't do that and have to be given very specific instructions'. Five of the nine teachers interviewed expressed the view that they assumed that students would come to secondary school equipped with sound information retrieval skills, although their views were not based on empirical evidence. The other teachers were less certain about what skills students might be taught in primary school.

In terms of students transferring information retrieval skills, the teachers took a uniform view that most students would not transfer skills without prompting. Most teachers saw some students as being capable of transfer and identified these students as the most able. Teachers were divided in their reasons for lack of transfer. Some teachers argued that, for many year seven students, transfer was a difficult concept, while others argued that students took a very compartmentalized view of school subjects and that this restricted transfer.

The interviews with the teacher librarians showed that they had more knowledge of students' experience of information retrieval skills in primary schools. This was mainly because it was the teacher librarians who were seen as responsible for teaching information retrieval skills to year seven students in these schools. The view of all the teacher librarians was that students' experience of information retrieval depended on which primary school students had attended. The teacher librarians expressed much less confidence than the teachers in the level students' information retrieval skills. The School A teacher librarian summed this up, stating that while students were good at finding books, 'most students still search Google with single keywords - and pick the first site they find'.

The teacher librarians agreed with the teachers that few students were likely to transfer information retrieval skills, despite being taught these skills in sessions in the library. The School B teacher librarian, for example, stated 'Most of the students seem to forget what I've told them before, say about using the OPAC or using keywords when searching the web'. The teacher librarians agreed with the teachers that students tended to view information skills as discrete and not to be transferred unless told to do so.

In the theoretical sampling interviews, the teachers and teacher librarians were interviewed together. The groups were firstly asked about whether students made connections, especially between concept mapping and information retrieval, and information retrieval and assignment writing. The staff were divided on the extent to which students made connections, with some teachers and teacher librarians arguing that most students did make connections, for example in using concept map keywords when searching for information. Other staff agreed, but argued that only a minority made effective connections, and that only this minority understood the full value of making connections. The groups were agreed that all but a small minority of students valued information retrieval skills, but they were also agreed that most students did not translate this value into action, particularly in relation to transfer.

Where the teachers and teacher librarians differed from their students was in relation to who was responsible for encouraging students to transfer information 
retrieval skills. Staff were divided into those who thought that students should take responsibility for transferring skills and those who thought that staff should be responsible. A School B teacher summed up the views of those focusing on students, stating 'They are too product orientated. They want to rush to get assignments done and they see information retrieval skills - say like doing a proper search on Google - as time wasting'. Staff taking this view argued that even if information retrieval skills were reinforced, students' attitudes would prevent transfer. Other staff disagreed, arguing that it was the teachers' and teacher librarians' responsibility to reinforce information retrieval skills, and other skills, across the curriculum. One of the teacher librarians argued that 'We need to get students to break down the barriers they see between subjects'. All staff were agreed that there was no culture of transfer in any of the schools and that this could be a hindrance to the transfer of skills.

\section{Discussion}

The interpretation of the data by the researcher focused on: students valuing information retrieval skills; students making connections between information retrieval skills and other information literacy skills; factors affecting the transfer of information retrieval skills; and culture of transfer

\section{Students valuing information retrieval skills}

This author defines value in terms of students recognising the importance of information retrieval skills and identifying benefits from having such skills. This could be contrasted with a more practical approach to information retrieval skills, in that students might well make use of such skills, but would not value them e.g. by reflecting on importance of using such skills. The students who valued information retrieval skills, did so in different ways. The evidence from this study showed that a minority of students valued information retrieval skills, in that they reflected on the use of these skills and how they might improve their use of such skills in the future. This group of students put these skills into practice and were able to evaluate the effectiveness of different search strategies when using search engines. These students had acquired information retrieval as an ability and a reflective practice.

The majority of students in these schools valued information retrieval skills, but in a narrower, more utilitarian manner. These students recognised how effective information retrieval benefitted them in finding relevant information for their assignments, but they did not reflect on their use of searching skills. This large group of students may be seen as viewing information retrieval skills as a means to an end i.e. finding information for a particular assignment. These students had acquired information retrieval more as a set of skills than an ability. While this group put their skills into practice, it was not a reflective practice.

A third group of students - a very small minority - did not value information retrieval skills, as they failed to understand what benefits might be gained from using these skills. The evidence showed that this very small group of students found the concept of effective information retrieval very difficult. For example, 
while they understood the mechanics of searching on Google, they were unable to reflect on what effective searching might be. This group merely acquired some mechanical aspects of information retrieval, but they can be seen as not acquiring information retrieval either as a reflective skills or practice.

While there has been much attention to examining students' information retrieval skills in the literature (Kuhlthau 2004, Chung and Neuman 2007, Myers et al 2006, and Chelton and Cool 2004), little attention has been paid to the question of whether students value these skills. It is clear from this study that teaching students to value information retrieval skills, as well as to implement these skills effectively, will have an effect on how students find and use information, concepts and ideas for their assignments.

Students making connections between information retrieval skills and other information literacy skills

One of the distinguishing features between the three groups of students identified from this study was the ability of some students to think about information retrieval skills in a reflective manner, and to make connections between information retrieval skills and other information literacy skills. The students who most valued information retrieval skills engaged in critical thinking about these skills, in that they evaluated different searching techniques and strategies, and they also made connections between information retrieval skills and other skills. These students can be seen as taking a much more holistic view of their use of information literacy skills than other students. This holistic view can be seen where this small group of students made clear connections between using either question formulation or concept mapping, and information retrieval. These students reflected on the importance of developing their search strategies based on their concept map or their self-generated questions. These students also reflected on the importance of effective information retrieval not only for finding information on their topic, but for finding relevant information and ideas which suited the structure of their assignment. Making connections for these students fitted into their acquired ability and reflective practice.

The second and larger group of students did make connections but in a much narrower sense. While some of this group connected the concept map or questions to searching for relevant information, the group as a whole did not tend to make connections beyond the information retrieval stage. The limited connection made by this group reflects their use of information retrieval more as a skill than an ability and reflective practice. The third group of students did not make connections as they failed to understand why they should make such connections, and this was influenced by their failure to understand the concept of effective information retrieval.

In the literature on information literacy in schools, Moore (2002), Kuhlthau (2004), Barranoik (2004), Ryan and Hudson (2003) and Author (2006) discuss aspects of students' reflecting on the skills they use, and the critical and reflective group of students referred to above fall into the same category as those students identified by Wolf (2003) who demonstrated metacognitive attributes amongst some students. The literature tends not to focus directly on the value of making connections, but rather implies that students might make such connections. 


\section{Factors affecting the transfer of information retrieval skills}

In relation to transfer, this study found that students could be grouped in a similar way to value. The minority of students who extensively valued information retrieval skills were most likely to transfer these skills across time and subjects, without intervention by teachers or teacher librarians. This group may be seen as actual transferrers, in that they were able to take a metacognitive view of how information retrieval skills fitted in with their own learning, and how transferring these skills would be of benefit to them. This group may also be seen as reflective transferrers. By acquiring information retrieval as an ability and reflective practice, transferring what they had learned about information retrieval fitted into the approach of these students.

The majority of students were identified as propositional transferrers of information retrieval skills. The evidence showed that these students recognised value in information retrieval skills and agreed that, in theory, these skills should be transferred. In practice, this group of students was unlikely to transfer information retrieval skills without being prompted to do so by teachers or teacher librarians. The reasons for this lack of transfer appeared to be complex, but included student motivation as well as what students viewed as received practice. The propositional transferrer group's concept of received practice included the view that unless teachers or teacher librarians specifically told them to transfer information retrieval skills, then they had no need to do so, and this attitude made these students less motivated to transfer skills. These students may be seen as skills oriented rather than ability oriented, in that they lacked the reflective ability to judge the value of transfer.

The third group can be viewed as non-transferrers, as these students lacked the ability to understand the concept of transfer, and saw no value in transferring information retrieval skills. Unlike the propositional transferrers, these students lacked the ability to judge whether the transfer of information retrieval skills would benefit them. While there is a range of literature on transfer in schools (Royer et al 2005), and while research done by Kuhlthau (2004) and Bilal et al (2008) imply that transfer may be important, there has been a distinct lack of focus on the transfer of information retrieval skills, apart from Author and Hurst (2006).

\section{Culture of transfer}

It was clear that there was little evidence of a culture of transfer in these schools. Where schools have a culture of transfer, teachers and teacher librarians would recognise the importance of transfer, and actively promote the transfer of skills across the school, both formally and informally. In the theoretical sampling interviews with staff, it was acknowledged that a culture of transfer did not exist in any of the schools, despite widespread belief in transfer as a key educational skill. Staff acknowledged, for example, that the concept of transfer was never discussed with students. These schools assumed that the transfer of knowledge and skills such as information retrieval skills would take place, but took no action to ensure that transfer would occur. In these schools, there was a lack of any formal policy or overall commitment to the transfer of information retrieval skills, and other information literacy skills, and it was clear that without such a policy or 
commitment, only a minority of students were likely to transfer. The sociocultural view of transfer taken in this study implies that there needs to be more than a formal policy on the transfer of skills in these schools, and that attitudes of staff and students to transfer will play a key factor in developing students who view the transfer of skills as important. Haskell (2001) argued strongly for schools to establish a culture of transfer, and a culture of transfer is implied, rather than stated, by Royer et al (2005). There appears to be no references to a culture of transfer in the information literacy in schools literature.

\section{Implications for teacher librarians and teachers in schools}

There is a range of implications for teacher librarians and teachers from this research and these include:

- The need for more attention to be paid to encouraging students to value information retrieval skills before they implement them, and this suggests that teacher librarians consider revising the way they teach information retrieval skills

- The need for teacher librarians and teachers to evaluate the extent to which information retrieval skills are taught and reinforced across the curriculum, and this suggests that teacher librarians may need to explore the extent to which teachers value and can effectively use information retrieval skills

- The need for schools to develop a culture of transfer for information retrieval skills (and other information literacy skills), and this suggest that schools try to develop a commitment to transfer by both staff and students

- The need for more research in relation to information retrieval skills, which takes a wider view of the relationship of these skills to aspects of student learning in schools.

\section{References}

Barranoik, L., (2004) Students and their research: architects of meaning. SCAN, 23 (2), 33-37.

Bilal, D., Sarangthem, S. and Bachir, I. (2008) Toward a model of children's information seeking behavior in using digital libraries. In: Proceedings of the second international symposium on Information interaction in context, London, United Kingdom. 145-151. ACM, New York.

Charmaz, K. (2006) Constructing grounded theory: a practical guide through qualitative analysis. London: Sage.

Chelton, M. and Cool, C. (2004) Youth information seeking behavior: Theories, models, and Issues. Lanham, MD: Rowan and Littlefield.

Chung, J. and Neuman, D. (2007) High school students' information seeking and use for class projects. Journal of the American Society for Information Science and Technology, $\mathbf{5 8}$ (10), 1503-1517. 
Detterman, D. (1993) The case for the prosecution: transfer as an epiphenomenon In: Detterman, D. and Sternberg, R. (eds.) Transfer on trial: intelligence, cognition and instruction. Norwood, NJ.: Ablex Publishing.

Farmer, L. (2005) Social-emotional behavior and information literacy In: Lee, S, Warning, P., Singh, D., Howe, E., Farmer, L. and Hughes, S. (Eds.) IASL Reports 2005: Information leadership in a culture of change. Erie, PA: International Association of School Librarianship.

Glaser, B. and Strauss, A. (1967) The discovery of grounded theory: strategies for qualitative research. Chicago: Aldine.

Gross, M. (2004) Children's Information Seeking at School: Findings from a qualitative Study. In: Chelton, M. and Cool, C. Youth Information-seeking behaviour: theories, models and issues. Lanham, MD: Scarecrow Press.

Hakel, M. and Halpern, D. (2005). How far can transfer go? In Mestre, J. (ed.), Transfer of learning from a modern multidisciplinary perspective. Greenwich, CT.: Information Age Publishing.

Haskell, R. (2001) Transfer of learning: cognition, instruction and reasoning. San Diego: Academic Press

Herring, James Edward (1996) Teaching information skills in schools. London: Library Association Publishing.

Author. (2004) The internet and information skills in schools: a guide for teachers and school librarians. London: Facet Publishing.

Herring, James Edward (2006) A critical investigation of students' and teachers' views of the use of information literacy skills in school assignments. School Library Media Research, (9) [online], URL: http://www.ala.org/ala/aasl/aaslpubsandjournals/slmrb/slmrcontents/volume9/info rmationliteracy.cfm [accessed 12.05.10].

Herring, James Edward and Hurst, J. (2006) An investigation into the extent to which Year 6 students transfer information literacy across subjects In McGregor, J. and Hay, L. (eds.), Research in Teacher Librarianship: Proceedings of the Centre for Studies in Teacher Librarianship Research Conference, Australian National University, Canberra, 9-10 April 2005. [online], URL: http://www.csu.edu.au/faculty/educat/sis/CIS/epubs/CSTLpapers.htm [accessed 12.05.10].

Herring, James Edward and Tarter, A-M (2007). Progress in developing information literacy in a secondary school using the PLUS model. School Libraries in View, 23, 3-7.

Herring, James Edward, Tarter, A-M. and Naylor, S. (2002) An evaluation of the PLUS model to develop pupils' information skills in a secondary school. School Libraries Worldwide, 1, 1-24.

Kuhlthau, C. (2004) Seeking meaning: a process approach to library and information services. $2^{\text {nd }}$ ed., Westport CT.: Libraries Unlimited. 
Lloyd, A. (2007) Recasting information literacy as sociocultural practice: implications for library and information science researchers. Information Research, 12 (4). [online] URL: http://informationr.net/ir/12-4/colis/colis34.html [accessed 12.05.10].

Loertscher, D. (2008) Information literacy: 20 years later. Teacher Librarian, 35 (5), 42-43.

Myers, E., Nathan, L. and Saxton, M. (2007) Barriers to information seeking in school libraries: conflicts in perceptions and practice. Information Research, 11 (2). [online], URL: http://informationr.net/ir/12-2/paper295.html [accessed 12.05.10].

Phillips, D. (1995) The good, the bad and the ugly: The many faces of constructivism. Educational Researcher, 24 (7), 5-12.

Pidgeon, N. and Henwood, K. (2004) Grounded theory. In: Hardy, M. and Bryman, A. (eds). Handbook of Data Analysis. London: Sage.

Royer, J. Mestre, J. and Dufresne, R. (2005) Introduction: framing the transfer problem In: Mestre, J (Ed.). Transfer of learning from a modern multidisciplinary perspective. Greenwich, CT.: Information Age Publishing.

Strauss, A. and Corbin, J. (1998) Basics of qualitative research ( $2^{\text {nd }}$ Ed.). London: Sage.

Todd, R., (2007) Guided inquiry supporting information literacy, Scan, 26 (2), 2829.

Wolf, S. (2007) Information literacy and self-regulation: A convergence of disciplines. School Library Media Research, 10. [online], URL:

http://www.ala.org/ala/aas1/aaslpubsandjournals/slmrb/slmrcontents/volume10/wo If_informationliteracy.cfm [accessed 12.05.10]

Woolls, B. \& Loertscher, D. (2002) Information literacy: A review of the research: A guide for practitioners and researchers. 2nd ed., San José, CA.: Hi Willow Research and Publishing

\section{Open access and copyright}

Library and Information Research is an open access journal. A freely available copy of this paper may be downloaded from the journal's website:

http://www.cilipjournals.org.uk/lir

Copyright and associated moral rights in works published in Library and Information Research are retained by the author(s) but this paper may be used freely, with proper attribution, in educational and other non-commercial settings. 